\title{
Formação de professores: aspectos históricos e teóricos do problema no contexto brasileiro*
}

\section{Dermeval Saviani}

Universidade Estadual de Campinas, Faculdade de Educação

\section{Aspectos históricos}

A necessidade da formação docente já fora preconizada por Comenius, no século XVII, e o primeiro estabelecimento de ensino destinado à formação de professores teria sido instituído por São João Batista de La Salle em 1684, em Reims, com o nome de Seminário dos Mestres (Duarte, 1986, p. 65-66). Mas a questão da formação de professores exigiu uma resposta institucional apenas no século XIX, quando, após a Revolução Francesa, foi colocado o problema da instrução popular. É daí que deriva o processo de criação de Escolas Normais como instituições encarregadas de preparar professores.

A primeira instituição com o nome de Escola Normal foi proposta pela convenção, em 1794 e instalada em Paris em 1795. Já a partir desse momento se introduziu a distinção entre Escola Normal Superior para formar professores de nível secundário e Escola Normal simplesmente, também chamada Escola Nor-

* Trabalho apresentado na $31^{\text {a }}$ Reunião Anual da ANPEd, realizada de 16 a 20 de outubro de 2008, em Caxambu (MG). mal Primária, para preparar os professores do ensino primário. Assim é que Napoleão, ao conquistar o Norte da Itália, instituiu, em 1802, a Escola Normal de Pisa nos moldes da Escola Normal Superior de Paris. Essa escola, da mesma forma que seu modelo francês, destinava-se à formação de professores para o ensino secundário, mas na prática se transformou em uma instituição de altos estudos, deixando de lado qualquer preocupação com o preparo didático-pedagógico. Além de França e Itália, países como Alemanha, Inglaterra e Estados Unidos também foram instalando, ao longo do século XIX, suas Escolas Normais.

No Brasil a questão do preparo de professores emerge de forma explícita após a independência, quando se cogita da organização da instrução popular. A partir daí, examinando-se a questão pedagógica em articulação com as transformações que se processaram na sociedade brasileira ao longo dos últimos dois séculos, podemos distinguir os seguintes períodos na história da formação de professores no Brasil:

1. Ensaios intermitentes de formação de professores (1827-1890). Esse período se inicia com 
o dispositivo da Lei das Escolas de Primeiras Letras, que obrigava os professores a se instruir no método do ensino mútuo, às próprias expensas; estende-se até 1890, quando prevalece o modelo das Escolas Normais.

2. Estabelecimento e expansão do padrão das Escolas Normais (1890-1932), cujo marco inicial é a reforma paulista da Escola Normal tendo como anexo a escola-modelo.

3. Organização dos Institutos de Educação (19321939), cujos marcos são as reformas de Anísio Teixeira no Distrito Federal, em 1932, e de Fernando de Azevedo em São Paulo, em 1933.

4. Organização e implantação dos Cursos de Pedagogia e de Licenciatura e consolidação do modelo das Escolas Normais (1939-1971).

5. Substituição da Escola Normal pela Habilitação Específica de Magistério (1971-1996).

6. Advento dos Institutos Superiores de Educação, Escolas Normais Superiores e o novo perfil do Curso de Pedagogia (1996-2006).

Passemos em revista, de forma sucinta, cada um desses períodos. ${ }^{1}$

\section{Ensaios intermitentes de formação de professores (1827-1890)}

Durante todo o período colonial, desde os colégios jesuítas, passando pelas aulas régias implantadas pelas reformas pombalinas até os cursos superiores criados a partir da vinda de D. João VI em 1808, não se manifesta preocupação explícita com a questão da formação de professores. É na Lei das Escolas de Primeiras Letras, promulgada em 15 de outubro de

${ }^{1}$ Essa análise dos períodos incorpora as considerações feitas no trabalho "Pedagogia e formação de professores no Brasil: vicissitudes dos dois últimos séculos”, apresentado na sessão de Comunicação Coordenada Permanências e mudanças na educação brasileira - séculos XIX e XX, no IV Congresso Brasileiro de História da Educação, realizado em Goiânia (GO) de 5 a 8 de novembro de 2006.
1827, que essa preocupação apareceu pela primeira vez. Ao determinar que o ensino, nessas escolas, deveria ser desenvolvido pelo método mútuo, a referida lei estipula no artigo $4^{\circ}$ que os professores deverão ser treinados nesse método, às próprias custas, nas capitais das respectivas províncias. Portanto, está colocada aí a exigência de preparo didático, embora não se faça referência propriamente à questão pedagógica.

Após a promulgação do Ato Adicional de 1834, que colocou a instrução primária sob responsabilidade das províncias, estas tendem a adotar, para formação dos professores, a via que vinha sendo seguida nos países europeus: a criação de Escolas Normais. A Província do Rio de Janeiro sai à frente, instituindo em Niterói, já em 1835, a primeira Escola Normal do país. Esse caminho foi seguido pela maioria das províncias ainda no século XIX, na seguinte ordem: Bahia, 1836; Mato Grosso, 1842; São Paulo, 1846; Piauí, 1864; Rio Grande do Sul, 1869; Paraná e Sergipe, 1870; Espírito Santo e Rio Grande do Norte, 1873; Paraíba, 1879; Rio de Janeiro (DF) e Santa Catarina, 1880; Goiás, 1884; Ceará, 1885; Maranhão, 1890. Essas escolas, entretanto, tiveram existência intermitente, sendo fechadas e reabertas periodicamente.

Visando à preparação de professores para as escolas primárias, as Escolas Normais preconizavam uma formação específica. Logo, deveriam guiar-se pelas coordenadas pedagógico-didáticas. No entanto, contrariamente a essa expectativa, predominou nelas a preocupação com o domínio dos conhecimentos a serem transmitidos nas escolas de primeiras letras. $\mathrm{O}$ currículo dessas escolas era constituído pelas mesmas matérias ensinadas nas escolas de primeiras letras. Portanto, o que se pressupunha era que os professores deveriam ter o domínio daqueles conteúdos que lhes caberia transmitir às crianças, desconsiderando-se o preparo didático-pedagógico.

A via normalista de formação docente, embora adotada já a partir de 1835, além de somente adquirir certa estabilidade após 1870, permaneceu ao longo do século XIX como uma alternativa sujeita a contestações. Ilustra isso a posição de Couto Ferraz, que considerava as Escolas Normais muito onerosas, ineficientes quali- 
tativamente e insignificantes quantitativamente, pois era muito pequeno o número de alunos formados. Por isso, Couto Ferraz, quando presidente da Província do Rio de Janeiro, fechou a Escola Normal de Niterói em 1849, substituindo-a pelos professores adjuntos, regime que adotou no Regulamento de 1854 ao exercer o cargo de ministro do Império. Os adjuntos atuariam nas escolas como ajudantes do regente de classe, aperfeiçoando-se nas matérias e práticas de ensino. Por esse meio seriam preparados os novos professores, dispensando-se a instalação de Escolas Normais. Mas esse caminho não prosperou. Os cursos normais continuaram a ser instalados, e a pioneira escola de Niterói foi reaberta em 1859.

\section{Estabelecimento e expansão do padrão das Escolas Normais (1890-1932)}

Pode-se considerar que o padrão de organização e funcionamento das Escolas Normais foi fixado com a reforma da instrução pública do estado de São Paulo levada a efeito em 1890. Segundo os reformadores, "sem professores bem preparados, praticamente instruídos nos modernos processos pedagógicos e com cabedal científico adequado às necessidades da vida atual, o ensino não pode ser regenerador e eficaz" (São Paulo, 1890). E mestres assim qualificados "só poderão sair de escolas normais organizadas em condições de prepará-los” (Reis Filho, 1995, p. 44). Portanto, uma vez que a Escola Normal então existente pecava "por insuficiência do seu programa de estudo e pela carência de preparo prático dos seus alunos" (São Paulo, 1890), era imperioso reformar seu plano de estudos.

A reforma foi marcada por dois vetores: enriquecimento dos conteúdos curriculares anteriores e ênfase nos exercícios práticos de ensino, cuja marca característica foi a criação da escola-modelo anexa à Escola Normal - na verdade a principal inovação da reforma. Assumindo os custos de sua instalação e centralizando o preparo dos novos professores nos exercícios práticos, os reformadores estavam assumindo o entendimento de que, sem assegurar de forma deliberada e sistemática por meio da organização curricular a preparação pedagógico-didática, não se estaria, em sentido próprio, formando professores.

Essa reforma da Escola Normal da capital se estendeu para as principais cidades do interior do estado de São Paulo e se tornou referência para outros estados do país, que enviavam seus educadores para observar e estagiar em São Paulo ou recebiam “missões” de professores paulistas. Dessa forma, o padrão da Escola Normal tendeu a se firmar e se expandir por todo o país.

\section{Organização dos institutos de educação (1932- 1939)}

Ainda que o padrão da Escola Normal se tenha fixado a partir da reforma paulista, após a primeira década republicana o ímpeto reformador se arrefeceu. E a expansão desse padrão não se traduziu em avanços muito significativos, trazendo ainda a marca da força do padrão até então dominante, centrado na preocupação com o domínio dos conhecimentos a serem transmitidos.

Uma nova fase se abriu com o advento dos institutos de educação, concebidos como espaços de cultivo da educação, encarada não apenas como objeto do ensino mas também da pesquisa. Nesse âmbito, as duas principais iniciativas foram o Instituto de Educação do Distrito Federal, concebido e implantado por Anísio Teixeira em 1932 e dirigido por Lourenço Filho; e o Instituto de Educação de São Paulo, implantado em 1933 por Fernando de Azevedo. Ambos sob inspiração do ideário da Escola Nova.

Com a reforma instituída pelo decreto n. 3.810, de 19 de março de 1932, Anísio Teixeira se propôs a erradicar aquilo que ele considerava o "vício de constituição” das Escolas Normais, que, “pretendendo ser, ao mesmo tempo, escolas de cultura geral e de cultura profissional, falhavam lamentavelmente nos dois objetivos" (Vidal, 2001, p. 79-80). Para esse fim, transformou a Escola Normal em Escola de Professores, cujo currículo incluía, já no primeiro ano, as seguintes disciplinas: 1) biologia educacional; 2) sociologia educacional; 3) psicologia educacional; 4) história da educação; 5) introdução ao ensino, contemplando 
três aspectos: a) princípios e técnicas; b) matérias de ensino abrangendo cálculo, leitura e linguagem, literatura infantil, estudos sociais e ciências naturais; c) prática de ensino, realizada mediante observação, experimentação e participação. como suporte ao caráter prático do processo formativo, a escola de professores contava com uma estrutura de apoio que envolvia: a) jardim de infância, escola primária e escola secundária, que funcionavam como campo de experimentação, demonstração e prática de ensino; b) instituto de pesquisas educacionais; c) biblioteca central de educação; d) bibliotecas escolares; e) filmoteca; f) museus escolares; g) radiodifusão.

O Instituto de Educação de São Paulo seguiu, sob a gestão de Fernando de Azevedo, um caminho semelhante, com a criação, também aí, da Escola de Professores (Monarcha, 1999, p. 324-336).

Pelo exposto, percebe-se que os institutos de educação foram pensados e organizados de maneira a incorporar as exigências da pedagogia, que buscava se firmar como um conhecimento de caráter científico. Caminhava-se, pois, decisivamente rumo à consolidação do modelo pedagógico-didático de formação docente que permitiria corrigir as insuficiências e distorções das velhas Escolas Normais caracterizadas por "um curso híbrido, que oferecia, ao lado de um exíguo currículo profissional, um ensino de humanidades e ciências quantitativamente mais significativo" (Tanuri, 2000, p. 72).

\section{Organização e implantação dos cursos de pedagogia e de licenciatura e consolidação do padrão das Escolas Normais (1939-1971)}

Os Institutos de Educação do Distrito Federal e de São Paulo foram elevados ao nível universitário, tornando-se a base dos estudos superiores de educação: o paulista foi incorporado à Universidade de São Paulo, fundada em 1934, e o carioca foi incorporado à Universidade do Distrito Federal, criada em 1935. E foi sobre essa base que se organizaram os cursos de formação de professores para as escolas secundárias, generalizados para todo o país a partir do decreto-lei n. 1.190, de 4 de abril de 1939, que deu organização definitiva à Faculdade Nacional de Filosofia da Universidade do Brasil. Sendo esta instituição considerada referência para as demais escolas de nível superior, o paradigma resultante do decreto-lei n. 1.190 se estendeu para todo o país, compondo o modelo que ficou conhecido como "esquema $3+1$ " adotado na organização dos cursos de licenciatura e de Pedagogia. Os primeiros formavam os professores para ministrar as várias disciplinas que compunham os currículos das escolas secundárias; os segundos formavam os professores para exercer a docência nas Escolas Normais. Em ambos os casos vigorava o mesmo esquema: três anos para o estudo das disciplinas específicas, vale dizer, os conteúdos cognitivos ou "os cursos de matérias”, na expressão de Anísio Teixeira, e um ano para a formação didática.

Cabe observar que, ao ser generalizado, o modelo de formação de professores em nível superior perdeu sua referência de origem, cujo suporte eram as escolas experimentais às quais competia fornecer uma base de pesquisa que pretendia dar caráter científico aos processos formativos.

A mesma orientação prevaleceu, no que se refere ao ensino normal, com a aprovação em âmbito nacional do decreto-lei n. 8.530, de 2 de janeiro de 1946, conhecido como Lei Orgânica do Ensino Normal (Brasil, 1946). Na nova estrutura, o curso normal, em simetria com os demais cursos de nível secundário, foi dividido em dois ciclos: o primeiro correspondia ao ciclo ginasial do curso secundário e tinha duração de quatro anos. Seu objetivo era formar regentes do ensino primário e funcionaria em Escolas Normais regionais. O segundo ciclo, com a duração de três anos, correspondia ao ciclo colegial do curso secundário. Seu objetivo era formar os professores do ensino primário e funcionaria em Escolas Normais e nos institutos de educação. Estes, além dos cursos citados, contariam com jardim de infância e escola primária anexos e ministrariam também cursos de especialização de professores primários para as áreas de Educação Especial, Ensino Supletivo, Desenho e Artes aplicadas, música e canto e cursos de adminis- 
tradores escolares para formar diretores, orientadores e inspetores escolares.

Se os cursos normais de primeiro ciclo, pela sua similitude com os ginásios, tinham um currículo centrado nas disciplinas de cultura geral, no estilo das velhas Escolas Normais, tão criticadas, os cursos de segundo ciclo contemplavam todos os fundamentos da educação introduzidos pelas reformas da década de 1930.

Mas, ao serem implantados, tanto os cursos normais como os de licenciatura e Pedagogia centraram a formação no aspecto profissional garantido por um currículo composto por um conjunto de disciplinas a serem frequentadas pelos alunos, dispensada a exigência de escolas-laboratório. Essa situação, especialmente no nível superior, expressou-se numa solução dualista: os cursos de licenciatura resultaram fortemente marcados pelos conteúdos culturais-cognitivos, relegando o aspecto pedagógico-didático a um apêndice de menor importância, representado pelo curso de didática, encarado como uma mera exigência formal para a obtenção do registro profissional de professor. $\mathrm{O}$ curso de Pedagogia, à semelhança do que ocorreu com os cursos normais, foi marcado por uma tensão entre os dois modelos. Embora seu objeto próprio estivesse todo ele embebido do caráter pedagógico-didático, este tendeu a ser interpretado como um conteúdo a ser transmitido aos alunos antes que como algo a ser assimilado teórica e praticamente para assegurar a eficácia qualitativa da ação docente. Consequentemente, o aspecto pedagógico-didático, em lugar de se constituir em um novo modelo a impregnar todo o processo da formação docente, foi incorporado sob a égide do modelo dos conteúdos culturais-cognitivos.

\section{Substituição da Escola Normal pela habilitação específica de Magistério (1971-1996)}

O golpe militar de 1964 exigiu adequações no campo educacional efetivadas mediante mudanças na legislação do ensino. Em decorrência, a lei n. 5.692/71 (Brasil, 1971) modificou os ensinos primário e médio, alterando sua denominação respectivamente para primeiro grau e segundo grau. Nessa nova estrutura, desapareceram as Escolas Normais. Em seu lugar foi instituída a habilitação específica de $2^{\circ}$ grau para o exercício do magistério de $1^{\circ}$ grau (HEM). Pelo parecer n. 349/72 (Brasil-MEC-CFE, 1972), aprovado em 6 de abril de 1972, a habilitação específica do magistério foi organizada em duas modalidades básicas: uma com a duração de três anos (2.200 horas), que habilitaria a lecionar até a $4^{\mathrm{a}}$ série; e outra com a duração de quatro anos (2.900 horas), habilitando ao magistério até a $6^{\text {a }}$ série do $1^{\circ}$ grau. O currículo mínimo compreendia o núcleo comum, obrigatório em todo o território nacional para todo o ensino de $1^{\circ}$ e $2^{\circ}$ graus, destinado a garantir a formação geral; e uma parte diversificada, visando à formação especial. $\mathrm{O}$ antigo curso normal cedeu lugar a uma habilitação de $2^{\circ}$ Grau. A formação de professores para o antigo ensino primário foi, pois, reduzida a uma habilitação dispersa em meio a tantas outras, configurando um quadro de precariedade bastante preocupante.

A evidência e gravidade dos problemas levaram o governo a lançar, em 1982, o projeto Centros de Formação e Aperfeiçoamento do Magistério (CEFAMs), que teve o caráter de "revitalização da Escola Normal" (Cavalcante, 1994, p. 59, 76 e 123). Mas esse projeto, apesar dos resultados positivos, foi descontinuado quando seu alcance quantitativo era ainda restrito, não tendo havido também qualquer política para o aproveitamento dos professores formados pelos centros nas redes escolares públicas.

Para as quatro últimas séries do ensino de $1^{\circ}$ grau e para o ensino de $2^{\circ}$ grau, a lei n. 5.692/71 previu a formação de professores em nível superior, em cursos de licenciatura curta (3 anos de duração) ou plena (4 anos de duração). Ao curso de Pedagogia, além da formação de professores para habilitação específica de Magistério (HEM), conferiu-se a atribuição de formar os especialistas em Educação, aí compreendidos os diretores de escola, orientadores educacionais, supervisores escolares e inspetores de ensino.

Paralelamente a esse ordenamento legal, desencadeou-se, a partir de 1980, um amplo movimento pela reformulação dos cursos de Pedagogia e licenciatura 
que adotou o princípio da "docência como a base da identidade profissional de todos os profissionais da educação” (Silva, 2003, p. 68 e 79). À luz desse princípio, a maioria das instituições tendeu a situar como atribuição dos cursos de Pedagogia a formação de professores para a educação infantil e para as séries iniciais do ensino de $1^{\circ}$ grau (ensino fundamental).

\section{Advento dos Institutos Superiores de Educação e das Escolas Normais Superiores (1996-2006)}

O quadro de mobilização dos educadores alimentou a expectativa de que, findo o regime militar, o problema da formação docente no Brasil seria mais bem equacionado. Mas a nova LDB promulgada, após diversas vicissitudes, em 20 de dezembro de 1996, não correspondeu a essa expectativa. Introduzindo como alternativa aos cursos de pedagogia e licenciatura os institutos superiores de educação e as Escolas Normais Superiores, a LDB sinalizou para uma política educacional tendente a efetuar um nivelamento por baixo: os institutos superiores de educação emergem como instituições de nível superior de segunda categoria, provendo uma formação mais aligeirada, mais barata, por meio de cursos de curta duração (Saviani, 2008c, p. 218-221). A essas características não ficaram imunes as novas diretrizes curriculares do curso de pedagogia homologadas em abril de 2006.

Como conclusão desse rápido escorço histórico constatamos que, ao longo dos últimos dois séculos, as sucessivas mudanças introduzidas no processo de formação docente revelam um quadro de descontinuidade, embora sem rupturas. A questão pedagógica, de início ausente, vai penetrando lentamente até ocupar posição central nos ensaios de reformas da década de 1930. Mas não encontrou, até hoje, um encaminhamento satisfatório. Ao fim e ao cabo, o que se revela permanente no decorrer dos seis períodos analisados é a precariedade das políticas formativas, cujas sucessivas mudanças não lograram estabelecer um padrão minimamente consistente de preparação docente para fazer face aos problemas enfrentados pela educação escolar em nosso país.
Visando a encontrar caminhos que nos permitam superar as dificuldades detectadas, impõe-se examinar os aspectos teóricos da questão.

\section{Aspectos teóricos}

Se o problema da formação de professores se configurou a partir do século XIX, isso não significa que o fenômeno da formação de professores tenha surgido apenas nesse momento. Antes disso havia escolas, tipificadas pelas universidades instituídas desde o século XI e pelos colégios de humanidades que se expandiram a partir do século XVII. Ora, nessas instituições havia professores e estes deviam, por certo, receber algum tipo de formação. Ocorre que, até então, prevalecia o princípio do "aprender fazendo”, próprio das corporações de ofício (Santoni Rugiu, 1998). E as universidades, como modalidade de corporação que se dedicava às assim chamadas “artes liberais” ou intelectuais, por oposição às “artes mecânicas" ou manuais, formavam os professores das escolas inferiores ao ensinar-lhes os conhecimentos que deveriam transmitir nas referidas escolas. Porém, a partir do século XIX, a necessidade de universalizar a instrução elementar conduziu à organização dos sistemas nacionais de ensino. Estes, concebidos como um conjunto amplo constituído por grande número de escolas organizadas segundo um mesmo padrão, viram-se diante do problema de formar professores também em grande escala - para atuar nas escolas. E o caminho encontrado para equacionar essa questão foi a criação de Escolas Normais, de nível médio, para formar professores primários atribuindo-se ao nível superior a tarefa de formar os professores secundários.

\section{Modelos contrapostos de formação de professores}

Nesse contexto configuraram-se dois modelos de formação de professores:

a) modelo dos conteúdos culturais-cognitivos: para este modelo, a formação do professor se 
esgota na cultura geral e no domínio específico dos conteúdos da área de conhecimento correspondente à disciplina que irá lecionar.

b) modelo pedagógico-didático: contrapondo-se ao anterior, este modelo considera que a formação do professor propriamente dita só se completa com o efetivo preparo pedagógicodidático.

Em verdade, quando se afirma que a universidade não tem interesse pelo problema da formação de professores, o que se está querendo dizer é que ela nunca se preocupou com a formação específica, isto é, com o preparo pedagógico-didático dos professores. De fato, o que está em causa aí não é propriamente uma omissão da universidade em relação ao problema da formação dos professores, mas a luta entre dois modelos diferentes de formação. De um lado está o modelo para o qual a formação de professores propriamente dita se esgota na cultura geral e no domínio específico dos conteúdos da área de conhecimento correspondente à disciplina que o professor irá lecionar. Considera-se que a formação pedagógico-didática virá em decorrência do domínio dos conteúdos do conhecimento logicamente organizado, sendo adquirida na própria prática docente ou mediante mecanismos do tipo “treinamento em serviço”. Em qualquer hipótese, não cabe à universidade essa ordem de preocupações.

A esse modelo se contrapõe aquele segundo o qual a formação de professores só se completa com o efetivo preparo pedagógico-didático. Em consequência, além da cultura geral e da formação específica na área de conhecimento correspondente, a instituição formadora deverá assegurar, de forma deliberada e sistemática por meio da organização curricular, a preparação pedagógico-didática, sem a qual não estará, em sentido próprio, formando professores.

\section{Modelos de formação docente na história da formação de professores}

Na história da formação de professores constatamos que o primeiro modelo predominou nas uni- versidades e demais instituições de ensino superior que se encarregaram da formação dos professores secundários, ao passo que o segundo tendeu a prevalecer nas Escolas Normais, ou seja, na formação dos professores primários.

Para que possamos compreender adequadamente esse fenômeno, convém ter presente que as universidades, na sua configuração contemporânea, caracterizam-se por três elementos interligados, mas com pesos diferentes: o Estado, a sociedade civil e a autonomia da comunidade acadêmica. A prevalência do Estado dá origem ao modelo napoleônico; prevalecendo a sociedade civil tem-se o modelo anglo-saxônico; e sobre a autonomia da comunidade acadêmica se funda o modelo prussiano.

Nos casos em que predomina o modelo napoleônico, ainda que sob a aparência de caótica diversidade, as universidades tendem, por indução do Estado, a se unificar estruturalmente sob um ordenamento comum e com os mesmos currículos formativos. E o currículo formativo posto em posição dominante para os professores da escola secundária é aquele centrado nos conteúdos culturais-cognitivos, dispensada qualquer preocupação com o preparo pedagógico-didático. Isso se compreende quando se considera que, sob a hegemonia de uma elite de corte liberal-burguês, a escola secundária foi definida como o lugar da distinção de classe cujo papel é garantir aos membros da elite o domínio daqueles conteúdos que a distinguem do povo-massa. Nesse quadro, os referidos conteúdos são considerados formativos em si mesmos, não deixando margem a veleidades pedagógicas. Com efeito, o modelo pedagógico-didático pressupõe, desde Comenius, que todo e qualquer conteúdo, quando considerado adequadamente à vista das condições do ser que aprende, é suscetível de ser ensinado a todos os membros da espécie humana. Tal modelo é, pois, antielitista por excelência.

Na universidade brasileira, apesar de uma certa influência em nível organizacional do modelo anglosaxônico pela via dos Estados Unidos, prevalece o modelo napoleônico. E também aí tradicionalmente se tem emprestado à escola secundária o papel de 
distinção de classe. Em consequência, não deixa de estar presente também no ethos dos professores universitários brasileiros uma certa depreciação do aspecto pedagógico. Entretanto, seja pela influência anglo-saxônica, seja porque as desigualdades extremas obrigam a uma maior sensibilidade para o aspecto educativo, no Brasil o modelo pedagógicodidático conseguiu abrir espaços no nível de organização dos currículos formativos tornando-se, pela via legal e também por iniciativas autônomas de algumas universidades que ampliam os requisitos legais, um componente obrigatório na formação dos professores secundários. Mas essa obrigatoriedade legal reveste-se, com frequência, de um formalismo que esvazia o sentido real desses componentes formativos. Isso pode ser observado na organização dos cursos de licenciatura desde o chamado esquema 3+1 das décadas de 1940 e 1950, nos bacharelados complementados pelas disciplinas pedagógicas a cargo dos departamentos de Pedagogia das faculdades de Filosofia, Ciências e Letras na década de 1960, as quais passaram, na reforma que entrou em vigor na década de 1970, para a alçada das faculdades de Educação.

Diante das considerações apresentadas, reforçase em nós a convicção de que o problema dos cursos de Licenciatura - isto é, o problema da formação dos professores das quatro últimas séries do ensino fundamental e do ensino médio - não será resolvido sem o concurso das Faculdades de Educação; mas também não será resolvido apenas por elas nem mesmo pela justaposição, aos atuais currículos dos cursos de bacharelado, de um currículo pedagógico-didático organizado e operado pelas faculdades de Educação.

A formação profissional dos professores implica, pois, objetivos e competências específicas, requerendo em consequência estrutura organizacional adequada e diretamente voltada ao cumprimento dessa função. Para essa nova estrutura deverão confluir os elementos, sejam eles das diferentes faculdades ou institutos, sejam da faculdade de Educação, atualmente separados pela dualidade - a nosso ver artificial - dos cursos de bacharelado e de licenciatura.

\section{Possibilidades e riscos da formação de professores para a educação infantil e séries iniciais do ensino fundamental em nível superior}

No caso da formação de professores para as quatro primeiras séries do ensino fundamental, a instituição das Escolas Normais, que veio a se consolidar ao longo do século XX até a década de 1960, expressou a predominância do modelo pedagógico-didático, articulando, de forma mais ou menos satisfatória, os aspectos do conteúdo e da forma que caracterizam o processo de ensino. Atualmente, à vista do dispositivo legal que eleva essa formação para o nível superior, encontramo-nos diante de dois aspectos que se contrapõem. Com efeito, por um lado, a elevação ao nível superior permitiria esperar que, sobre a base da cultura geral de base clássica e científica obtida nos cursos de nível médio, os futuros professores poderiam adquirir, nos cursos formativos de nível superior, um preparo profissional bem mais consistente, alicerçado numa sólida cultura pedagógica. Por outro lado, entretanto, manifesta-se o risco de que essa formação seja neutralizada pela força do modelo dos conteúdos culturais-cognitivos, com o que as exigências pedagógicas tenderiam a ser secundarizadas. Com isso, esses novos professores terão grande dificuldade de atender às necessidades específicas das crianças pequenas, tanto no nível da chamada educação infantil como das primeiras séries do ensino fundamental.

O risco acima indicado é tanto mais real quando se sabe que no Brasil consagrou-se no nível do ensino superior uma estrutura que acopla os dois aspectos do processo de ensino referidos, considerados competências de duas unidades universitárias distintas que se justapõem na tarefa de formar os novos professores: o domínio dos conteúdos específicos da área a ser ensinada é atribuído aos institutos ou faculdades específicas; e o preparo pedagógico-didático fica a cargo das Faculdades de Educação.

\section{Dilemas da formação de professores}

A questão da formação de professores é atravessada por vários dilemas. Aqui, porém, será abordado 
apenas aquele derivado dos dois modelos mencionados de formação docente. ${ }^{2}$ Dilema é, como registram os dicionários, uma "situação embaraçosa com duas saídas igualmente difíceis”; é exatamente essa a situação da formação de professores diante do confronto entre os dois modelos: aquele centrado nos conteúdos culturais-cognitivos e aquele referido ao aspecto pedagógico-didático.

O dilema se expressa do seguinte modo: admitese que os dois aspectos - os conteúdos de conhecimento e os procedimentos didático-pedagógicos - devam integrar o processo de formação de professores. Como, porém, articulá-los adequadamente? A ênfase nos conhecimentos que constituem a matéria dos currículos escolares leva a dar precedência ao modelo dos conteúdos culturais-cognitivos. Nesse caso, na organização institucional, seríamos levados a situar a questão da formação de professores no âmbito dos institutos ou faculdades específicos. Inversamente, se nosso ponto de partida for o modelo pedagógicodidático, tenderemos a situar os cursos no âmbito das faculdades de educação.

No entanto, levando em conta as tentativas feitas desde 1980 a partir do movimento pró-reformulação dos cursos de Pedagogia e licenciatura, constatamos que as duas saídas apontadas resultam igualmente problemáticas, mantendo-se o caráter embaraçoso da situação.

Tudo indica que na raiz desse dilema está a dissociação entre os dois aspectos indissociáveis da função docente: a forma e o conteúdo. Considerando o modo como estão constituídas as especializações universitárias, dir-se-ia que os estudantes, que vivenciaram na educação básica a unidade dos dois aspectos, ao ingressar no ensino superior terão adquirido o direito de se fixar apenas em um deles. Em consequência, os que foram aprovados no vestibular de Pedagogia não precisam mais se preocupar com os conteúdos. E os que foram aprovados nos vestibulares das diferentes

\footnotetext{
${ }^{2} \mathrm{O}$ conteúdo deste e do próximo tópico pode ser aprofundado recorrendo à conclusão da Parte II do livro A pedagogia no Brasil: história e teoria (Saviani, 2008a, p. 149-161).
}

disciplinas de licenciatura se concentram apenas nos respectivos conteúdos específicos, despreocupando-se com as formas a eles correspondentes.

Em decorrência, constata-se que as faculdades de Educação tendem a reunir os especialistas das formas abstraídas dos conteúdos, enquanto os institutos e faculdades correspondentes às disciplinas que compõem os currículos escolares reúnem os especialistas nos conteúdos abstraídos das formas que os veiculam. Ora, se na raiz do dilema está a dissociação entre os dois aspectos que caracterizam a função docente, compreende-se que ambos os modelos desemboquem em saídas embaraçosas, isto é, que não resolvem o dilema em que eles próprios se constituem. Segue-se, pois, que as duas vias propostas constituem os elementos do próprio problema cuja solução se busca, não podendo ser, pois, alternativas para resolvê-lo.

Quais seriam, então, as perspectivas de solução do dilema?

\section{Tentando superar o dilema}

Considerando-se que o dilema resultou da dissociação de aspectos indissociáveis do ato docente, logicamente a saída do dilema implica a recuperação da referida indissociabilidade.

Uma vez que a dissociação se deu por um processo de abstração, para recuperar a indissociabilidade será necessário considerar o ato docente como fenômeno concreto, isto é, tal como ele se dá efetivamente no interior das escolas. Um caminho prático e objetivo para verificar a montagem e o modo de operar dos currículos escolares é partir dos livros didáticos, o que permitiria tomá-los como ponto de partida para a reformulação dos cursos de Pedagogia e dos demais cursos de licenciatura.

Dispondo os conhecimentos numa forma que visa viabilizar o processo de transmissão-assimilação que caracteriza a relação professor-aluno em sala de aula, mal ou bem os livros didáticos fazem a articulação entre a forma e o conteúdo. A questão pedagógica por excelência, que diz respeito à seleção, organização, distribuição, dosagem e sequenciação dos elementos 
relevantes para a formação dos educandos é, assim, realizada pelo livro didático no que se refere à pedagogia escolar; o livro se transforma, ainda que de modo “empírico”, isto é, sem consciência plena desse fato, no "grande pedagogo" de nossas escolas. Efetivamente, é ele que, geralmente de maneira acrítica, dá forma prática à teoria pedagógica nas suas diferentes versões.

$\mathrm{O}$ que foi dito pode ser verificado ao se constatar que, na medida em que se alteram as influências teórico-pedagógicas, os livros didáticos mudam de cara. Quando predominava a pedagogia tradicional, os livros didáticos eram sisudos, centravam-se nos conteúdos e se dirigiam ao intelecto dos alunos, solicitando sua capacidade de memorização. Quando passou a predominar a influência escolanovista, os livros didáticos se tornaram coloridos, ilustrados, com sugestões de atividades, buscando estimular a iniciativa dos alunos. E quando se difundiu a pedagogia tecnicista começaram a surgir livros didáticos descartáveis, com testes de escolha múltipla ou na forma de instrução programada.

Assim, analisando os livros didáticos adotados nas escolas, os cursos de pedagogia possibilitariam que os alunos efetuassem, a partir do estudo dos fundamentos da educação, a crítica pedagógica dos manuais de ensino, evidenciando seu alcance e seus limites, suas falhas e suas eventuais qualidades. Esse procedimento permitiria aos futuros pedagogos rememorar os conteúdos de ensino que eles já haviam aprendido nas escolas, porém de forma sincrética, isto é, sem consciência clara de suas relações. Agora, ao retomá-los no curso de pedagogia, os alunos teriam oportunidade de fazê-lo de modo sintético, isto é, com plena consciência das relações aí implicadas.

Por esse caminho, os cursos de pedagogia estariam formando profissionais capazes de atuar como orientadores, coordenadores pedagógicos, diretores, supervisores e como professores, seja nos cursos de magistério, seja nas escolas de educação infantil e nas cinco primeiras séries do ensino fundamental.

Mutatis mutandis, também os alunos dos cursos de licenciatura atingiriam, por meio da análise dos livros didáticos das áreas respectivas, uma com- preensão agora sintética e não mais apenas sincrética da relação entre forma e conteúdo no processo de ensino-aprendizagem.

Assim, recuperando a ligação entre os dois aspectos que caracterizam o ato docente, ou seja, evidenciando os processos didático-pedagógicos pelos quais os conteúdos se tornam assimiláveis pelos alunos no trabalho de ensino-aprendizagem, o dilema será superado.

Complementando essa reorganização dos currículos dos cursos de pedagogia e licenciatura, considerase que o caminho trilhado no âmbito da pesquisa para superar as compartimentalizações departamentais poderia ser tentado também no âmbito do ensino. Penso que chegou o momento de organizar grupos de ensino nas diferentes disciplinas dos currículos escolares que aglutinem docentes das Faculdades de Educação e das outras unidades acadêmicas em torno de projetos de ensino que configurariam as novas licenciaturas.

Espero que, pelo caminho sugerido, se delineiem perspectivas que permitam superar os dilemas com que nos debatemos hoje diante da tarefa relativa à formação de professores.

\section{Uma palavra sobre a educação especial}

Não se pode dizer que a educação especial não tenha sido contemplada na legislação em vigor. A LDB a definiu como uma modalidade de ensino e the dedicou um capítulo específico (Cap. V). Por sua vez, o Plano Nacional de Educação, após efetuar o diagnóstico e apresentar as diretrizes, fixa 28 objetivos e metas a serem atingidos nos dez anos de vigência do plano. E o Conselho Nacional de Educação elaborou o parecer CNE/CEB n. 17/2001, no qual tratou, com razoável minúcia, das diretrizes nacionais para a educação especial na educação básica, definindo-as na resolução n. 2, de 11 de setembro de 2001.

No entanto, no que se refere à formação de professores para atuar na Educação Especial a questão permanece em aberto. Com efeito, o lugar onde esse tipo de formação poderia ser contemplado em sua especificidade seria o curso de Pedagogia. Entretanto, 
a resolução CNE/CP 1, de 2006, que definiu as diretrizes curriculares nacionais para o curso de Pedagogia toca na questão da Educação Especial de passagem e apenas duas vezes. Trata-se do artigo $5^{\circ}$, inciso X (Saviani, 2008, p. 248): “demonstrar consciência da diversidade, respeitando as diferenças de natureza ambiental-ecológica, étnico-racial, de gêneros, faixas geracionais, classes sociais, religiões, necessidades especiais, escolhas sexuais, entre outras” (grifos meus) e do artigo $8^{\circ}$, inciso III (idem, ibidem, p. 251):

[...] atividades complementares envolvendo [...] opcionalmente, a educação de pessoas com necessidades especiais, a educação do campo, a educação indígena, a educação em remanescentes de quilombos, em organizações nãogovernamentais, escolares e não-escolares, públicas e privadas. (grifos meus)

Vê-se que, nos dois dispositivos, a referência à Educação Especial é claramente secundária. No primeiro caso, a menção não chega a ser à modalidade de ensino, mas apenas a situa no rol das várias situações demonstrativas da consciência da diversidade; no segundo caso, limita-se a uma atividade complementar, de caráter opcional, para efeitos de integralização de estudos.

Portanto, o quadro atual representa um retrocesso em relação ao período inaugurado em 1946 com a Lei Orgânica do Ensino Normal. Com efeito, como se indicou, essa legislação previa que os institutos de educação, além do ensino normal, ministrariam cursos de especialização para formar, entre outros, professores de Educação Especial.

Considerada a complexidade do problema inerente a essa modalidade, de certo modo evidenciada nos vários aspectos contemplados no próprio documento do Conselho Nacional de Educação que fixou as diretrizes curriculares nacionais para a Educação Especial na educação básica, será necessário instituir um espaço específico para cuidar da formação de professores para essa modalidade de ensino. Do contrário essa área continuará desguarnecida e de nada adiantarão as reiteradas proclamações referentes às virtudes da edu- cação inclusiva que povoam os documentos oficiais e boa parte da literatura educacional nos dias de hoje.

\section{Conclusão}

Ao encerrar esse trabalho não posso me furtar de chamar a atenção para o fato de que a questão da formação de professores não pode ser dissociada do problema das condições de trabalho que envolvem a carreira docente, em cujo âmbito devem ser equacionadas as questões do salário e da jornada de trabalho. Com efeito, as condições precárias de trabalho não apenas neutralizam a ação dos professores, mesmo que fossem bem formados. Tais condições dificultam também uma boa formação, pois operam como fator de desestímulo à procura pelos cursos de formação docente e à dedicação aos estudos.

Ora, tanto para garantir uma formação consistente como para assegurar condições adequadas de trabalho, faz-se necessário prover os recursos financeiros correspondentes. Aí está, portanto, o grande desafio a ser enfrentado. É preciso acabar com a duplicidade pela qual, ao mesmo tempo em que se proclamam aos quatro ventos as virtudes da educação exaltando sua importância decisiva num tipo de sociedade como esta em que vivemos, classificada como "sociedade do conhecimento”, as políticas predominantes se pautam pela busca da redução de custos, cortando investimentos. Faz-se necessário ajustar as decisões políticas ao discurso imperante.

Trata-se, pois, de eleger a educação como máxima prioridade, definindo-a como o eixo de um projeto de desenvolvimento nacional e, em consequência, carrear para ela todos os recursos disponíveis. Assim procedendo, estaríamos atacando de frente, e simultaneamente, outros problemas do país, como saúde, segurança, desemprego, pobreza, infraestrutura de transporte, de energia, abastecimento, meio ambiente etc. Infelizmente, porém, as tendências que vêm predominando na educação brasileira caminham na contramão dessa proposta.

Como assinalei na parte final da conclusão de meu livro Da nova LDB ao Fundeb (Saviani, 2008b, 
p. 323-324), não se trata de colocar a educação em competição com outras áreas necessitadas, como saúde, segurança, estradas, desemprego, pobreza etc. Ao contrário, sendo eleita eixo do projeto de desenvolvimento nacional, a educação será a via escolhida para atacar de frente todos esses problemas.

Com efeito, se ampliarmos o número de escolas, tornando-as capazes de absorver toda a população em idade escolar nos vários níveis e modalidades de ensino; se povoarmos essas escolas com todos os profissionais de que elas necessitam, em especial com professores em tempo integral e bem remunerados, nós estaremos atacando o problema do desemprego diretamente, pois serão criados milhões de empregos. Estaremos atacando o problema da segurança, pois estaremos retirando das ruas e do assédio do tráfico de drogas um grande contingente de crianças e jovens.

Mas, principalmente, estaremos atacando todos os demais problemas, pois estaremos promovendo o desenvolvimento econômico, uma vez que esses milhões de pessoas com bons salários irão consumir e, com isso, ativar o comércio, que, por sua vez, ativará o setor produtivo (indústria e agricultura), que irá produzir mais, contratar mais pessoas. De quebra, a implementação desse projeto provocará o crescimento exponencial da arrecadação de impostos. Com eles, o Estado poderá resolver os problemas de infraestrutura não apenas de transporte, mas também de energia, abastecimento, meio ambiente etc. e arcar com os programas sociais destinados aos então reduzidos grupos de não incluídos nesse amplo processo de desenvolvimento geral do país.

Enfim, é claro que, com esse projeto, será resolvido também o problema da qualidade da educação: transformada a docência numa profissão atraente socialmente em razão da sensível melhoria salarial e das boas condições de trabalho, para ela serão atraídos muitos jovens dispostos a investir seus recursos, tempo e energias numa alta qualificação obtida em graduações de longa duração e em cursos de pósgraduação. Com um quadro de professores altamente qualificado e fortemente motivado trabalhando em tempo integral numa única escola, estaremos forman- do os tão decantados cidadãos conscientes, críticos, criativos, esclarecidos e tecnicamente competentes para ocupar os postos do fervilhante mercado de trabalho de um país que viria a recuperar, a pleno vapor, sua capacidade produtiva. Estaria criado, por esse caminho, o tão desejado círculo virtuoso do desenvolvimento.

Trata-se de uma proposta ingênua, romântica? Não. Ela apenas extrai, com certo grau de radicalidade, as consequências do discurso hoje dominante. Se há uma pitada de ironia na forma em que foi enunciada, ela foi motivada pelo desejo de cobrar coerência aos portadores desse discurso.

Está lançado o desafio aos formadores de opinião, dirigentes dos vários níveis e dos mais diferentes ramos de atividade e, em especial, à classe política: ou assumimos essa proposta ou devemos deixar cair a máscara e parar de pronunciar discursos grandiloquentes sobre educação, em flagrante contradição com uma prática que nega cinicamente os discursos proferidos.

\section{Referências bibliográficas}

BRASIL. Decreto-lei 8.530, de 2 de janeiro de 1946. 1946. Disponível em: <www.soleis.adv.br>. Acesso em: 16 jan. 2009.

. Lei 5.692/71, de 11 de agosto de 1971. Diário Oficial da União, Brasília, 12 ago. 1971.

BRASIL/MEC/CFE. Parecer 349/72. Documenta, n. 137, p. 155173, abr. 1972.

BRASIL/MEC/CNE/CP. Resolução 1, de 15 de maio de 2006. In: SAVIANI, D. A pedagogia no Brasil: história e teoria. Campinas: Autores Associados, 2008. p. 246-253.

CAVALCANTE, Margarida Jardim. CEFAM: uma alternativa pedagógica para a formação do professor. São Paulo: Cortez, 1994. DUARTE, Sérgio Guerra. Dicionário brasileiro de educação. Rio de Janeiro: Antares/Nobel, 1986.

MONARCHA, Carlos. Escola normal da praça: o lado noturno das luzes. Campinas: Editora da UNICAMP, 1999.

REIS FILHO, Casemiro. A educação e a ilusão liberal. 2. ed. Campinas: Autores Associados, 1995.

SANTONI RUGIU, Antonio. Nostalgia do mestre artesão. Campinas: Autores Associados, 1998. 
Formação de professores: aspectos históricos e teóricos do problema no contexto brasileiro

SÃO PAULO. Decreto 27, de 12/03/1890. In: Coleção das Leis e Decretos do Estado de São Paulo. Tomo I - 1889-1891. São Paulo: Imprensa Oficial do Estado, 1909.

SAVIANI, Dermeval. A pedagogia no Brasil: história e teoria. Campinas: Autores Associados, 2008a.

. Da nova LDB ao FUNDEB: por uma outra política educacional. 2. ed. Campinas: Autores Associados, 2008b.

. A nova lei da educação (LDB): trajetória, limites e perspectivas. 11. ed. Campinas: Autores Associados, 2008c.

SILVA, Carmem Silvia Bissolli. Curso de pedagogia no Brasil: história e identidade. 2. ed. rev. e ampl. Campinas: Autores Associados, 2003.

TANURI, Leonor Maria. História da formação de professores. Revista Brasileira de Educação, n. 14, p. 61-88, maio/ago. 2000. VIDAL, Diana Gonçalves. O exercício disciplinado do olhar: livros, leituras e práticas de formação docente no Instituto de
Educação do Distrito Federal (1932-1937). Bragança Paulista: EDUSF, 2001.

DERMEVAL SAVIANI é professor emérito da Universidade Estadual de Campinas (UNICAMP), atuando nas áreas de teorias da educação, história da educação, política educacional, formação docente. Publicações recentes: Escola e democracia (Campinas: Autores Associados, 2008. Ed. especial comemorativa dos 25 anos de lançamento e da 40. ed.); Da nova LDB ao FUNDEB (Campinas: Autores Associados, 2007); História das ideias pedagógicas no Brasil (Campinas: Autores Associados, 2007); A pedagogia no Brasil: história e teoria (Campinas: Autores Associados, 2008). E-mail: dermevalsaviani@yahoo.com.br

Recebido em novembro de 2008 Aprovado em dezembro de 2008 